\title{
Microwave-assisted solvent- and catalyst-free synthesis of allylic thioetheres from allylic alcohols
}

\author{
Greice Tabarelli (PG)*, Marcelo Godoi (PG), Fábio Z. Galetto (PG), \\ Antonio Luiz Braga (PQ) \\ Universidade Federal de Santa Catarina \\ *greicetabarelli@yahoo.com.br
}

Keywords: allylic thioetheres, solvent free, microwave

\section{INTRODUCTION}

Allylic thioethers are versatile tools in organic synthesis, acting as precursors in enantioselective synthesis $^{1}$ as well as privileged substrates in crossmetathesis. ${ }^{2}$ Moreover these compounds are known to possess anticancer properties. ${ }^{3}$

Recently, the chemical literatures revels a great interest in the synthesis of allylic thioetheres. ${ }^{4}$ However, these methodologies require either Lewis or Brønsted acid to catalyze the synthesis of allylic thioetheres generating unwanted byproduct, beyond expensive cost of these catalyst.

In line with our interest in organochalcogenide ${ }^{5}$ herein we report the synthesis of allylic thioetheres under microwave irradiation and solvent- and catalyst-free conditions (Scheme 1).

\section{Scheme 1}

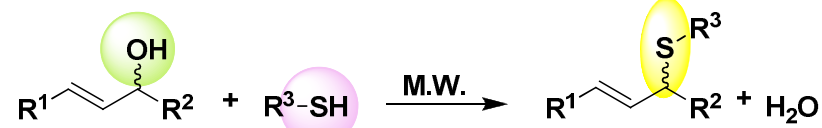

\section{RESULTS AND DISCUSSION}

Firstly we optimized the variation of microwave irradiation power and reaction time (Table 1).

Table 1. Optimization of the time and power.

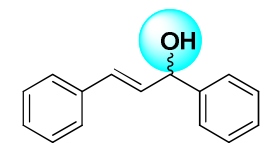

$1 a$

\begin{tabular}{cccc}
\multicolumn{1}{c}{ 1a } & 2a & 3a \\
\hline \# & Pot(W) & t(min) & Yield(\%) \\
\hline 1 & 50 & 5 & 62 \\
2 & 75 & 5 & 68 \\
3 & 100 & 5 & 73 \\
4 & 200 & 5 & 30 \\
5 & 100 & 10 & 81 \\
6 & 100 & 20 & 83 \\
\hline
\end{tabular}

Based on the results shown in Table 1, we observed that the best condition achieved was by using $100 \mathrm{~W}$ of power within $10 \mathrm{~min}$, where the desired product was obtained with $81 \%$ yield (Table 1, \# 5). Furthermore, we also check the influence of temperature on the reaction system (Table 2).

Table 2. Optimization of temperature ${ }^{a}$

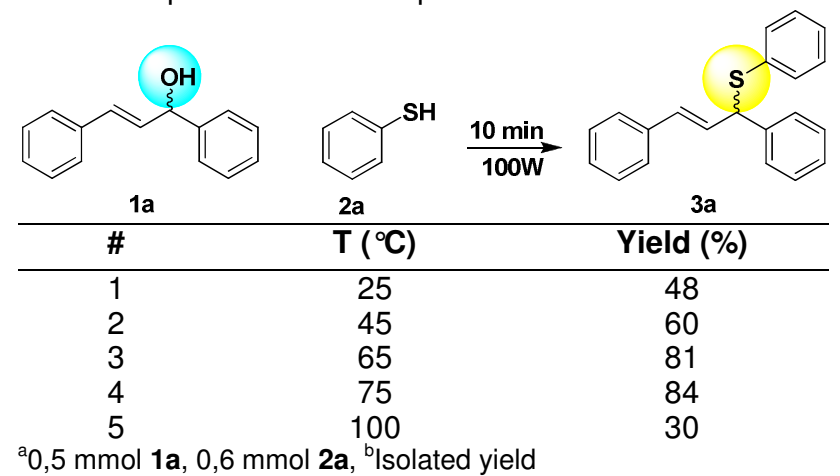

\section{CONCLUSION}

In summary, we have developed a straight forward method to synthesize allylic thioether in good yield. Studies for expanding of the scope of these reactions are currently in progress in our laboratory.

\section{ACKNOWLEDGEMENTS}

UFSC CAPES CNPq FAPESC INCT-catálise

\section{REFERENCES}

${ }^{1}$ D. W. McMillen, N. Varga, B.A. Reed, C. King, J. Org. Chem. 2000, 65, 2532-2536.

${ }^{2}$ Y. A. Lin, J.M. Chanlker, N. Floyde, G. J. L. Bernardes, B. G. Davis, J. Am. Chem. Soc. 2008, 130, 9642-9643.

${ }^{3}$ B. Marciniec, D. Chadyniak, S. Krompiec, J. Mol. Catal. 2004, 224, 111116.

${ }^{4}$ T. Kondo, T. Mitsudo. Chem. Rev, 2000, 100, 3205-3220.

${ }^{5}$ A. L. Braga, F. Z. Galetto, O. E. D. Rodrigues, C. S. Silveira, M. W Paixão. Chirality, 2008, 20, 839-845. 